\title{
Editorial
}

\section{Complementary and Alternative Medicine: a Japanese Perspective}

\author{
Nobutaka Suzuki, 13-1 Takaramachi, Kanazawa, Ishikawa 920-8640, Japan
}

The use of complementary and alternative medicine (CAM) is increasing rapidly. The World Health Organization (WHO) classifies $65-80 \%$ of the world's health care services as 'traditional medicine' (1). Therefore, from the viewpoint of the population ratio, more people use CAM than modern western medicine.

Although much attention has been focused on CAM not only from physicians but also basic medical researchers, scientific evidence for most CAM is still sparse. Emergence of CAM as a new current of medicine depends on whether or not precise scientific evidence can be accumulated.

Why has CAM become so popular among 'consumers'? I think that the following factors are responsible:

- CAM is easy to understand and familiar

- CAM is non-invasive, with few side effects

- CAM helps improve quality of life (QOL) or activity of daily life (ADL)

- CAM helps one to maintain one's own health

- Western modern medicine does not fully correspond to the patients' demands

- the trend towards a more holistic medical approach

- ballooning medical expenses

In this overview, I will describe and discuss the current status of CAM in Japan.

The situation in Japan should be of much interest, since Japan is unique as a country in which highly advanced modern Western medicine coexists with traditional Asian medicine.

\section{Classification of CAM}

CAM, as defined by The National Center for Complementary and Alternative Medicine (NCCAM) in the USA, is a group of diverse medical and health care systems, practices and products that are not presently considered to be part of conventional Western medicine. NCCAM classifies CAM therapies into five categories, or domains (Table 1).

In Japan, part of anti-aging medicine (growth hormone treatment, etc), lifestyle drugs (remedies for alopecia, obesity, impotence, etc) and 'environmental medicine' are considered to be included in CAM treatment. For example, developing a functional food which absorbs dioxins and promotes discharge into facilities, or developing a filter to trap the free radicals of automobile exhaust gas or cigarette smoke, etc, are included in the category of 'environmental medicine'.

The CAM domain in Japan also encompasses some forms of advanced medical treatments, which are not yet widely carried out, such as immunotherapy for cancer using tumor specific antigens, etc. In-vitro fertilization and embryo transfer (IVF/ET), one of the most advanced medical technologies, was regarded as CAM at the very beginning. Now, however, IVF/ET is widely used in conventional hospitals, so it can be said that some CAM modalities have been taken into conventional medical treatment. So, in Japan CAM has some connotations of 'frontier' medicine.

Unlike Western countries, in Japan, part of Kampo medicine (Japanese herbal medicine) and acupuncture are covered by public health insurance. Therefore, Japanese practitioners of Kampo and acupuncture would object to their inclusion in CAM and would rather regard themselves as belonging to the

Table 1. Classification of CAM therapies

\begin{tabular}{ll}
\hline 1. Alternative medical systems & $\begin{array}{l}\text { Traditional Chinese medicine, } \\
\text { Ayurveda, homeopathic medicine, } \\
\text { chiropractic, naturopathic } \\
\text { medicine, etc. }\end{array}$ \\
$\begin{array}{ll}\text { 2. Mind-body interventions } \\
\text { art, dance, music therapy, etc. }\end{array}$ \\
$\begin{array}{l}\text { Foods, herbs, vitamins, dietary } \\
\text { supplements, aromatherapy, etc. }\end{array}$ \\
$\begin{array}{l}\text { 4. Manipulative and body-based } \\
\text { methods }\end{array}$ \\
$\begin{array}{l}\text { Chiropractic or osteopathic } \\
\text { manipulation, and massage, etc. }\end{array}$ \\
$\begin{array}{l}\text { Biofield therapies } \\
\text { Bioelectromagnetic-based } \\
\text { therapies }\end{array}$ & Qi gong, therapeutic touch \\
& Electromagnetic fields
\end{tabular}

The online version of this article has been published under an open access model. Users are entitled to use, reproduce, disseminate, or display the open access version of this article provided that: the original authorship is properly and fully attributed; the Journal and Oxford University Press are attributed as the original place of publication with the correct citation details given; if an article is subsequently reproduced or disseminated not in its entirety but only in part or as a derivative work this must be clearly indicated. 


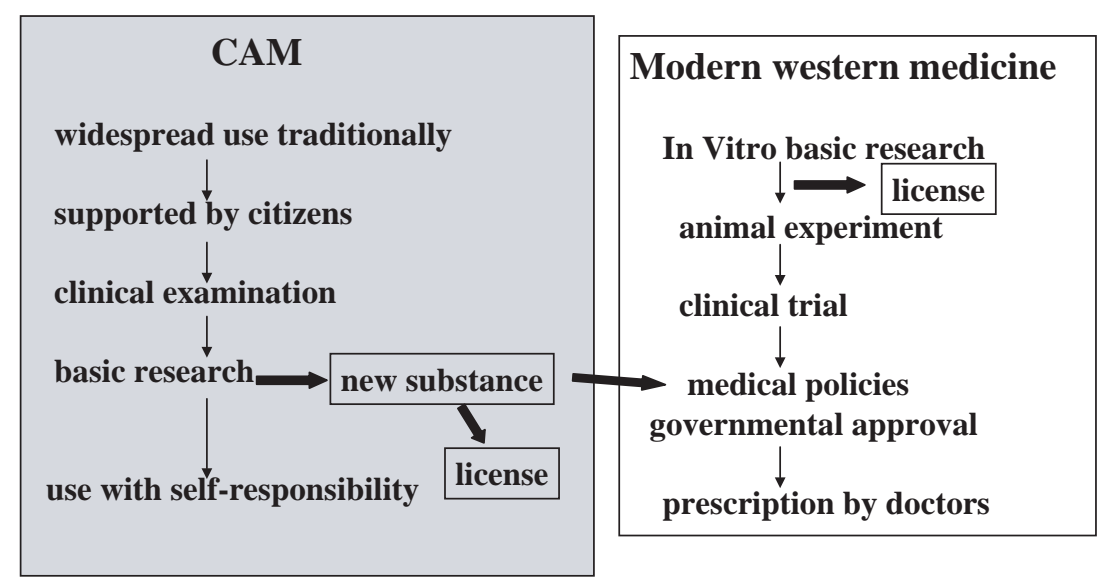

Figure 1. Flowchart of scientific research method.

authentic traditional medicine. However, these treatments are categorized as CAM in Europe and the USA. Thus, the definition of CAM differs slightly from country to country.

Japanese doctors' attitudes to CAM are unique, as found in the study carried out Imanishi et al. (2). Some form of complementary medicine was practiced by 267 of their respondents (73\%), the most common being Kampo (70\% of the respondents). Surprisingly, almost all doctors practicing complementary medicine were Kampo practitioners (96\%). A few doctors (8\%) practiced other forms of alternative medicine including chiropractic, aromatherapy, homeopathy, health spa therapy, Ayurveda, hypnosis, flower therapy, thalassotherapy, herb therapy, qigong, yoga, dietary therapy, imagery, meditation, art therapy and prayer. This result is very different from that of doctors in European and North American countries (3). Thus, Kampo is by far the most frequently practiced CAM modality by doctors themselves. I think this situation, namely adoption of Kampo by many doctors educated in Western medicine, is the most characteristic feature of CAM in Japan.

Acupuncture, electroacupuncture and moxibustion are practiced by acupuncturists and specialists in moxibustion rather than by doctors, because they need special training, unlike prescribing Kampo medicine. In Japan, after 3 years of education at a professional school of acupuncture, moxibustion, acupressure or massage, one can obtain a license to practice after passing the national examination. However, medical doctors are permitted to perform any one of the above treatments even if they do not attend one of these schools. However, not many medical doctors would actually be trained in the practice of these modalities. They are usually left to specialists.

Judo has been very popular since ancient times. Because injuries such as fracture or dislocation were frequent among judo wrestlers, unique orthopedic techniques have been developed by Judo practitioners over hundreds of years. The government thus recognizes Judo-Orthopedics as a distinct paramedical profession. To obtain a national license for Judo-Orthopedics, one must be educated for 3 years under licensed Judo orthodedicians. In contrast, chiropractic and osteopathy, which are widely used in the USA, are not authorized by the Japanese government.
Patients using CAM are not exclusively human. Recently, the popularity of pet ownership has risen in Japan. Since a pet is usually considered to be a member of the family, the owner is concerned that the pet receives good medical care, including CAM modalities. In response to owners' strong desires, CAM treatment by veterinarians is on the increase, including acupuncture, aromatherapy and herbal therapy. Of particular note is the widespread use of dietary supplements, thus many companies are researching and developing these specifically for animals.

\section{Validation of Traditional CAM Modalities: A Proposal}

In general, I believe CAM domains should be studied using the scientific research methods of modern Western medicine. However, for those traditional modalities which have already become part of the lifestyle in one country (or culture), their verification procedure would somewhat differ from that of Western modern medicine.

Figure 1 illustrates a proposed flowchart of the research method on CAM modalities, which have been traditionally employed without modern scientific endorsement. The first step should be focused on clinical trial to confirm efficacy and usefulness. Of course, before performing a clinical trial, it is necessary to complete safety testing in the modern scientific format, such as toxicity tests on animals. If the results of a clinical trial are desirable, basic research to identify and elucidate the action mechanism of the modality will be needed. Nowadays, users receive most CAM modalities at their own expense, but part of it may be able to gain government approval. I would like to point out that this is just the reverse order of when a new agent is introduced in modern Western medicine.

In Japan, more physicians are now attracted to CAM research, because they envisage that they will learn new medical methods, which have high practicality as well as high cost performance and safety. Furthermore, from the viewpoint of basic medicine, CAM offers unexpected opportunities to discover new substances and new mechanisms. 
Table 2. History of CAM (Japan and USA)

\begin{tabular}{lll}
\hline Year & Group/Association formed & Location \\
\hline 1990 & A small research group for CAM at Kanazawa University & Japan \\
1992 & Office of Alternative Medicine (OAM) in NIH & USA \\
1997 & Japanese Society for Complementary and Alternative Medicine (JCAM) & Japan \\
1998 & National Center for Complementary and Alternative Medicine (NCCAM) & USA \\
& Japanese Association for Alternative, Complementary and Traditional Medicine (JACT) & Japan \\
1999 & International Research Center for Traditional Medicine & Japan \\
2001 & Japanese Society for Integrative Medicine (JIM) & Japan \\
2002 & Department for Complementary and Alternative Medicine, Kanazawa University Graduate & Japan \\
\hline
\end{tabular}

\section{History of CAM: Japan and the USA Compared}

First of all, I wish to share the reason why I entered into this field. In 1990 I was working as a physician of obstetrics and gynecology at Keiju General Hospital in northern Japan. One day, I came across a curious case. I had planned to operate on an 18-year-old female patient who suffered from condyloma acuminatum. Condyloma acuminatum is a troublesome disease for ob/gyn physicians. It is hard to cure completely, and even after surgery patients still feel much pain. I was therefore not anticipating the operation with much enthusiasm. On the day of the operation, however, I was astonished to see that the lesions had completely disappeared. There should have been many condyloma lesions that had spread from the outer genitalia to the vaginal wall! Soon the reason for her spontaneous recovery became clear. Her grandmother had given her a kind of food that consisted of various natural products which mainly contained fermented coix seeds (a kind of wheat). She got the seeds from her grandmother, and was sure that it had worked wonders on the condyloma. This was my first contact with traditional folk medicine so effective as to outperform all of the Western medical modalities, including surgery, in which I had been trained. I have been interested in CAM from that time and now I am investigating the fundamental aspects and clinical efficacy of this food with my colleagues.

Table 2 shows the history of CAM in Japan and the USA. In 1990, soon after the above event, a small research group of physicians for CAM was born at Kanazawa University. In 1997, this group established the Japanese Society for Complementary and Alternative Medicine (JCAM). The members of JCAM are doctors, nurses, dentists, veterinarians, acupuncturists, nutritionists, pharmacists and researchers of various basic sciences. After the foundation of JCAM, another society, the Japanese Association for Alternative, Complementary and Traditional Medicine (JACT) and the Japanese Society for Integrative Medicine (JIM) were successively initiated. JACT is more interested in promoting collaboration among existing societies related to CAM and traditional medicine than exploring the CAM field per se.

The medical societies in Japan relevant to CAM domains are shown in Table 3. Most of these societies do not yet have a common commitment on CAM.
Table 3. Japanese societies in the domain of CAM

Japanese Society for Complementary and Alternative Medicine (JCAM)

Japanese Association for Alternative, Complementary and Traditional Medicine (JACT)

Japanese Society for Integrative Medicine (JIM)

Japanese Society of Aromatherapy

Japan Society of Acupuncture and Moxibustion

Japan Traditional Acupuncture and Moxibustion Society

Japan Dental Society of Oriental Medicine

Japan Society for Oriental Medicine

Medical and Pharmaceutical Society for WAKAN-YAKU

Japan Pre-symptomatic Medical System Society

Japanese Association of Physical medicine, Balneology and Climatology

Japanese Society of Psychopathology of Expression and Arts Therapy

Japanese Society of Biofeedback Research

Society of Hemorheology and Related Research

Japan Medical Conference on Magnetism

Japan Music Therapy Association

Japan Biomusic Association

Japan Fasting Therapy Society

others

In 1999, the International Research Center for Traditional Medicine was founded in Toyama prefecture. Research into Ayurveda (hot spring therapy) is being conducted (Fig. 2).

In 2002, the CAM department was founded at Kanazawa National University. I hope to introduce the activity of this department and education of CAM in a forthcoming Review article in this journal, which will focus on CAM research in Japan.

In the USA, to address the increasing need for research in CAM, Congress created the Office of Alternative Medicine (OAM) in 1992 at the National Institutes of Health (NIH). Funds allocated for the OAM were 2 million US dollars in 1992 and 1993, and steadily grew to 12 million US dollars in 1997 (1). In 1998, OAM came to be known as the National Center for Complementary and Alternative Medicine (NCCAM) (4). Now, the funds for NCCAM are over 100 million US dollars. NCCAM spends funds on CAM-related 

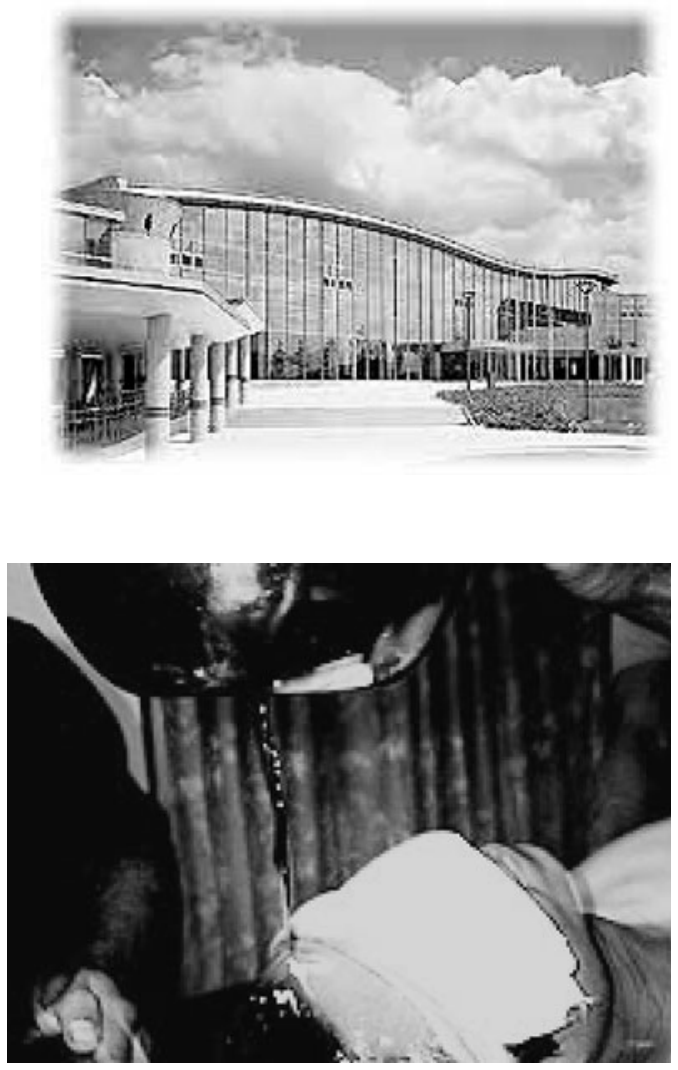

Ayurveda

Figure 2. International Research Center for Traditional Medicine.

research, and the major part of this research goes toward areas already largely accepted by conventional scientists, such as antioxidants or dietary manipulation.

\section{CAM in the Japanese Modern Western Medical Society}

Table 4 shows CAM symposia or lectures held by Japanese modern Western medical societies from 2002 to 2004, showing a significant change in the acceptance of CAM by these societies.

In 1999, ASCO (American Society of Clinical Oncology) held their 35th Annual Meeting. This congress included the symposium 'Alternative and Complementary Therapies and Oncologic Care'. Three years later, JSCO (Japan Society of Clinical Oncology) held their 40th Annual Meeting, including the symposium 'Alternative Medicine and Oncologic Care'.

Alternative medicine appeared in the Journal of the American Medical Association (JAMA) as a 'JAMA patient page. Alternative choices: what it means to use unconventional medicine' (5). Five years later, a lecture about CAM was given at The 26th General Assembly of the Japan Medical Congress. This is the biggest medical congress held every 4 years by the Japanese Medical Association. Thus, CAM is now rapidly entering into mainstream medicine in Japan.
Table 4. CAM symposia or lectures in the field of modern Western medical societies

\begin{tabular}{ll}
\hline Event & Date \\
\hline Japanese Society for Palliative Medicine & June 2002 \\
Japan Society of Clinical Oncology & October 2002 \\
General Assembly of the Japan Medical Congress & April 2003 \\
Japan Pediatric Society & April 2003 \\
Japan Society for Occupational Health & April 2003 \\
Japanese College of Surgeons & June 2003 \\
Japan Society of Obstetrics and Gynecology & October 2003 \\
Japanese Dermatological Association & November 2003 \\
Japan Epidemiological Association & January 2004 \\
Japanese Breast Cancer Society & June 2004 \\
\hline
\end{tabular}

\section{Attitude of the Japanese Government Toward CAM Domains}

In sharp contrast to the USA, the attitude of the Japanese government toward CAM was slow to change. This was partly because the government has long recognized traditional medical modalities, such as acupuncture and Kampo medicine as legitimate medical practice. But at the same time this slowness also shows that the government was not so interested in introducing any critical standards into various CAM modalities. Recently, however, an Advisory Panel of the Health, Labor and Welfare Ministry was established to investigate CAM in cancer therapy. Dr I. Hyodo of the National Shikoku Cancer Center is the chief of this committee. He stated that 'there is a lack of systematic research concerning the evidence of CAM efficacy. Many patients use CAM without enough accurate information. Many oncologists tend to ignore CAM use. Such circumstances should be improved as quickly as possible'. In 2002, Dr Hyodo and colleagues presented data of the cancer survey at the JSCO symposium mentioned above (Fig. 3). This initiative is symptomatic of the Japanese situation of CAM, where the most crucial problem, as perceived both by the government and the medical community, is that of widespread use without sufficient scientific evidence of various CAM modalities by cancer patients.

Furthermore, this committee reported on the perceptions and attitudes of clinical oncologists towards CAM (6). The CAM questionnaires were sent to 2118 clinical oncologists and found that the majority of oncologists $(82 \%)$ believed that CAM products were ineffective against cancer. The main reason for this belief was a lack of reliable information (as cited by $85 \%$ of oncologists). Only $13 \%$ of oncologists had experienced CAM-associated disease improvement in their cancer patients. Negative perceptions of CAM products persist among clinical oncologists. A lack of proven effectiveness of CAM products and concerns about drug interactions with anticancer treatment suggest a need for both accurate information on CAM products and clinical trials. The same opinion is expressed by others. For too long, the natural health products industry has kept its distance from medical research and from clinical medical practice, focusing instead on the short-term 


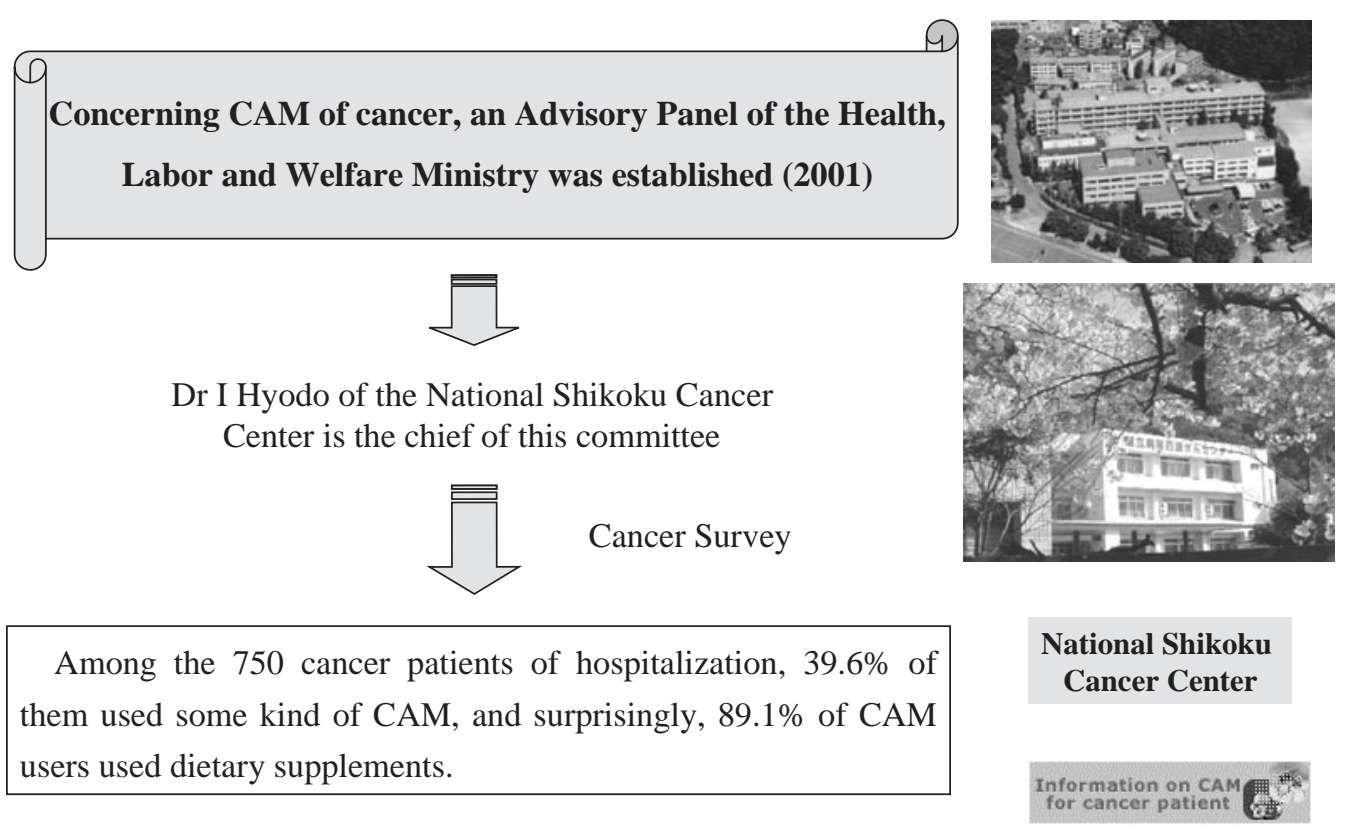

Figure 3. Cancer survey by Health, Labor and Welfare Ministry of Japan.

marketing advantages derived from keeping herbal and nutritional remedies exempt from Food and Drug Administration (FDA) review of efficacy. A wiser approach would be for the natural products industry to work with medical research, including the FDA, so that consumers and medical practitioners could be warned about potential harm and assured that the claimed health benefits were really there (7).

In 2003, the term 'CAM' was adopted as a new key word of 'the Grant-in-Aid for Scientific Research' of the Ministry of Education, Culture, Sports, Science and Technology. Because Japan does not yet have an organization like NCCAM, the CAM Department of Kanazawa University, which is a National University, has to play a pivotal role equivalent to that of NCCAM.

\section{Different CAM Modalities Used in Japan and the USA}

In the USA, CAM use increased from $33.8 \%$ in 1990 (8) to $42.1 \%$ in 1997 (9). CAM was used by $20-50 \%$ of the population in many European countries $(10,11)$ and $48.5 \%$ in Australia (12). In Japan, 65.6\% of adults used CAM (13) (Table 5). A telephone survey of 1000 Japanese respondents showed that the percentage of persons who had used at least one CAM modality over the previous 12 months was greater than the percentage of those who had used conventional Western medicine (76.0 versus $65.6 \%$ ) (14).

Furthermore, in the USA, $61.5 \%$ of the CAM users did not tell their doctors, while $78.9 \%$ of the CAM users in Japan did not tell theirs $(9,13)$.

Table 6 shows the type of CAM used in the USA and Japan. In Japan, the domain of dietary supplements is the most important, followed by aromatherapy, traditional Chinese medicine
Table 5. Prevalence of CAM in USA and Japan

\begin{tabular}{lll}
\hline USA & $42.1 \%$ of adults used CAM & Eisenberg et al. (9) \\
Japan & $65.6 \%$ of adults used CAM & Kamohara (13) \\
\hline
\end{tabular}

Table 6. Type of CAM in Japan and USA

\begin{tabular}{|c|c|c|}
\hline \multirow[t]{6}{*}{ Japan } & Dietary supplements & $42.0 \%$ \\
\hline & Massage & $31.2 \%$ \\
\hline & Reflexology & $20.2 \%$ \\
\hline & Aromatherapy & $14.6 \%$ \\
\hline & Acupressure & $13.2 \%$ \\
\hline & Herbs & $12.3 \%$ \\
\hline \multirow[t]{6}{*}{ USA } & Relaxation & $16.3 \%$ \\
\hline & Herbs & $12.1 \%$ \\
\hline & Massage & $11.1 \%$ \\
\hline & Chiropractic & $11.0 \%$ \\
\hline & Mental healing & $7.0 \%$ \\
\hline & Megavitamins & $5.5 \%$ \\
\hline
\end{tabular}

Sources: Kamohara (13), Eisenberg et al. (9).

(Kampo), Ayurveda and electromagnetic fields. In addition to these domains, hot spring bathing, lifestyle drugs, anti-aging medicine and environmental medicine are thought to be important. It should be noted that this is the order of CAM modalities employed by users themselves. As I stated above, Kampo medicine is by far the most frequently used modality in medical practice provided by licensed physicians.

A telephone survey revealed the percentage of use for each CAM therapy as follows: nutritional and tonic drinks, $43.1 \%$; dietary supplements, $43.1 \%$; health-related appliances, $21.5 \%$; 
herbs or over-the-counter Kampo, 17.2\%; massage or acupressure, $14.8 \%$; ethical Kampo (Kampo prescribed by medical doctors), 10.0\%; aromatherapy, 9.3\%; chiropractic or osteopathy, $7.1 \%$; acupuncture and moxibustion, $6.7 \%$; homeopathy, $0.3 \%$; other therapies, $6.5 \%$ (14). Regarding the reasons for the use of CAM, $60.4 \%$ responded that 'the condition was not serious enough to warrant conventional Western medicine', and $49.3 \%$ were 'expecting health enhancement or disease prevention'. The average annual out-of-pocket expenditures of all 1000 respondents were half as much for CAM as for conventional Western medicine (19 080 versus 38360 yen).

According to these data, CAM is very popular in Japan and the money spent is not negligible. It may strike the Western reader that Japanese people are not so much interested in the 'spiritual' modes of CAM, such as meditation and relaxation, as in the 'material' modes, such as dietary supplements, compared with American people. I believe this reflects some deep differences in the two cultures.

\section{Dietary Supplements in the USA and Japan}

Popular dietary supplements in the USA include Gingko Biloba, Echinacea, Garlic, Ginseng, Soybean, Saw Palmetto, St John's Wort, Valerian, Black Cohosh, Milk Thistle, Evening Primrose, Grape Seed Extract, Bilberry, Green Tea, Pycnogenol, Ginger, Feverfew and Dong quai, amongst others.

In Japan, an Agaricus blazei Murill is the most popular product. Many cancer patients take this mushroom. Beer yeast, Propolis, cereals, banaba, Japanese plum, Chlorella, barley verdure, vegetable juice, collagen, royal jelly and mulberry are also taken. These foods are quite different from the food supplements popular in the USA. For example, Dong quai is a food supplement in the USA but is classified as a medicine in Japan. Dong quai is one ingredient used in Kampo.

Faced with the high tide of demands from consumers for such various dietary supplements as above, the Japanese government introduced in 1993 a system of regulation on these products. Producers of these supplements are required to submit data to prove their efficacy in order to sell them as health dietary supplements, now called in translation 'Special Health Dietary Supplements (Tokuho)'. For example, a pharmaceutical company put into the market a kind of green tea containing high concentrations of catechin, for which they claim to have evidence that it helps consumers reduce body fat. As of the end of 2003, the market size was estimated to be around 5 billion US dollars. Dietary supplements are certainly one of those rare consumer goods, along with mobile phones and digital cameras, sales of which have shown a phenomenal growth in the otherwise sluggish Japanese economy of the last decade. Clearly, scientific evaluation has become a mandatory requirement to guide consumers (or patients) in choosing only those products that are truly beneficial for them.

\section{Conclusion}

I aimed in this Editorial to report the actual status of CAM in Japan. CAM usage has become increasingly common among Japanese citizens. Even though physicians are frequently requested by their patients to advise them about CAM, there is an absence of evidence for either efficacy or side effects for almost all specific treatments. Nor are there any reliable guidelines that could help integration of CAM modalities with conventional therapeutic modalities. Even so, courageous scientists and clinicians are taking this up as a challenge.

Just as outer space has been an unknown frontier for human beings from ancient times, the span of the domain of CAM is also beyond all expectations. CAM is filled with new and amazing discoveries, and it will increase people's welfare.

\section{Acknowledgments}

Preparation of this chapter was made possible through the efforts of Dr Masaki Inoue, Satoshi Ohno, Atsufumi Taru, Nobuo Yamaguchi, Yuji Kikuchi, Tsutomu Kamei and Miss Sayaka Shitano.

\section{References}

1. Jonas WB. Researching alternative medicine. Nat Med 1997;3:824-82.

2. Imanishi J, Watanabe S, Satoh M, Ozasa K. Japanese doctors' attitudes to complementary medicine. Lancet 1999;354:1735-6.

3. Austin JA, Marie A, Pelletier KR. A review of the incorporation of complementary and alternative medicine by mainstream physicians. Arch Intern Med 1998;158:2303-10.

4. Couzin J. Beefed-up NIH center probes unconventional therapies. Science 1998;282:2175-6.

5. Editor with JAMA. JAMA patient page; Alternative medicine. J Am Med Assoc 1998;280:1640.

6. Hyodo I, Eguchi K, Nishina T, Endo H, Tanimizu M, Mikami I, et al. Perceptions and attitudes of clinical oncologists on complementary and alternative medicine: a nationwide survey in Japan. Cancer 2003;97: 2861-8.

7. Koop CE. The Future of Medicine. Science 2002;295:233.

8. Eisenberg DM, Kessler RC, Foster C, Norlock FE, Calkins DR, Delbanco TL. Unconventional medicine in the United States. Prevalence, costs, and patterns of use. $N$ Engl J Med 1993;328:246-52.

9. Eisenberg DM, Davis RB, Ettner SJ, Wilkey S, Van S, Rompay M, et al. Trends in alternative medicine use in the United States, 1990-1997: results of a follow-up national survey. J Am Med Assoc 1998;280: $1569-75$.

10. Fisher P, Ward A. Complementary medicine in Europe. $\mathrm{Br}$ Med $\mathrm{J}$ 1994;309:107-11.

11. Fulder SJ, Munro RE. Complementary medicine in the United Kingdom: patients, practitioners, and consultations. Lancet 1985;2:542-5.

12. Maclennan AH, Wilson DH, Taylor AW. Prevalence and costs of alternative medicine in Australia. Lancet 1996;347:569-73.

13. Kamohara S. In Alternative Medicine, 1st Edition. Tokyo: Tyuou Kouron Shinsha, 2002; 30-5.

14. Yamashita H, Tsukayama H, Sugishita C. Popularity of complementary and alternative medicine in Japan: a telephone survey. Complement Ther Med 2002;10:84-93. 


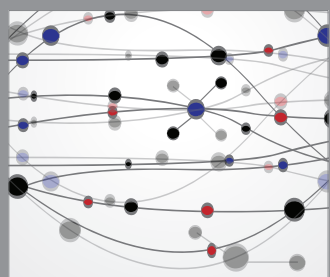

The Scientific World Journal
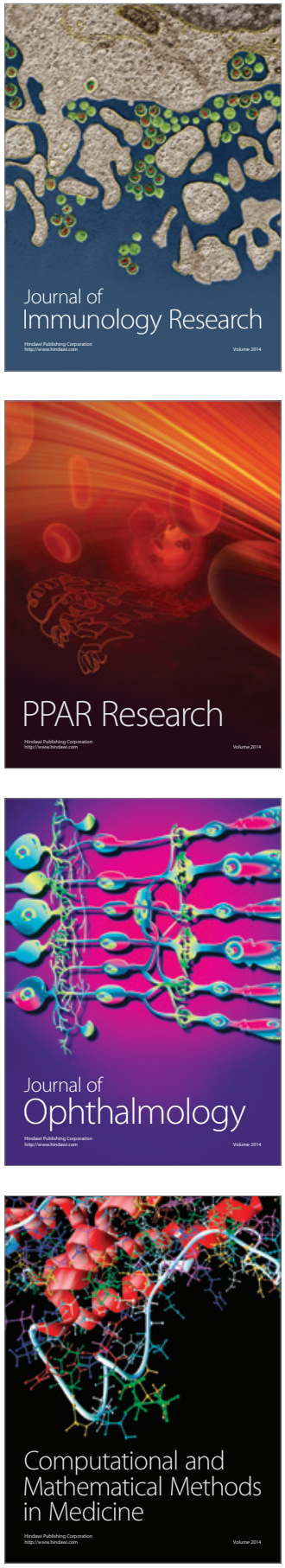

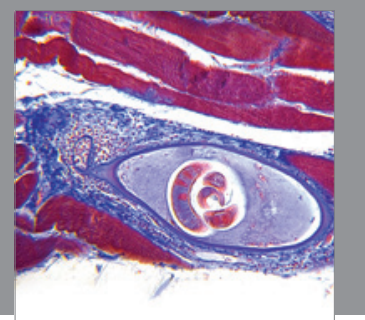

Gastroenterology

Research and Practice
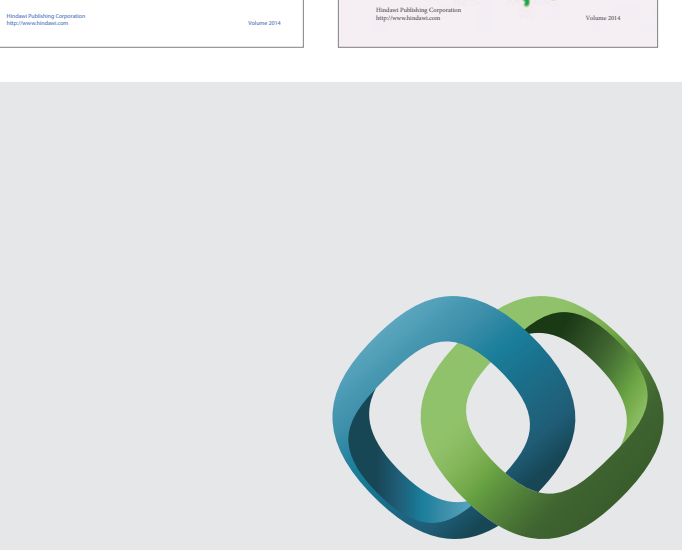

\section{Hindawi}

Submit your manuscripts at

http://www.hindawi.com
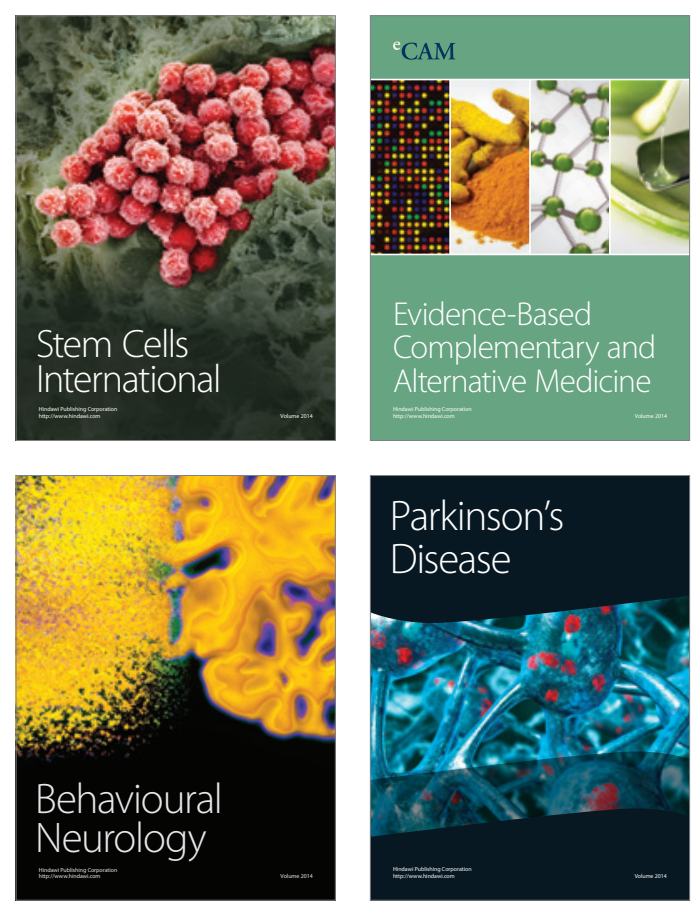

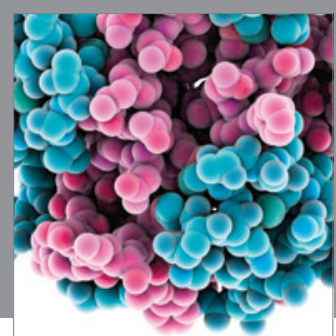

Journal of
Diabetes Research

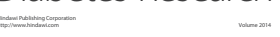

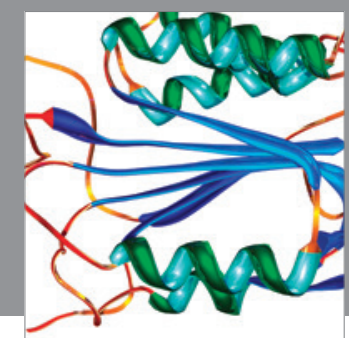

Disease Markers
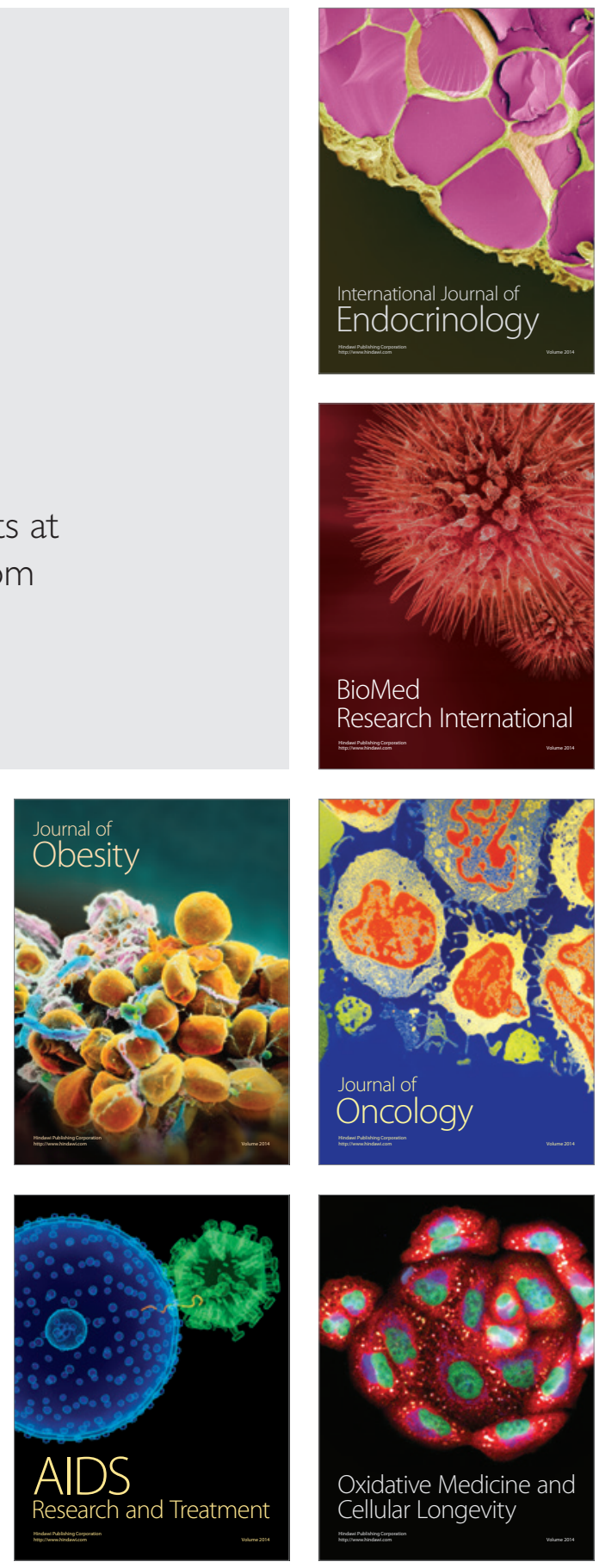